\title{
Isradipine Suppresses Amphetamine-Induced Conditioned Place Preference and Locomotor Stimulation in the Rat
}

\author{
Olgierd Pucilowski, M.D., Ph.D., Adam Plaźnik, M.D., Ph.D., \\ and David H. Overstreet, Ph.D.
}

The locomotor activating and the reinforcing effects of psychomotor stimulants are considered to be correlated with and responsible for the development and maintenance of stimulant addiction. Experiments were conducted to examine the effects of isradipine, the L-type calcium channel inhibitor, on the d-amphetamine-induced (1 $\mathrm{mg} / \mathrm{kg} I P$ ) reinforcement (conditioned place preference) and locomotor stimulation. Isradipine dose-dependently $(0.6,1.2,2.5 \mathrm{mg} / \mathrm{kg} \mathrm{IP})$ attenuated the reinforcing effect of amphetamine. Two higher doses completely blocked the induction of place preference. At these doses isradipine also prevented the increase in the number of intercompartment crosses that was observed in both amphetamine- and vehicle-treated controls. In an acute experiment, isradipine failed to affect locomotor activity on its own either in the place preference boxes or in the open field. Amphetamine increased the open field activity but did not change the number of crosses in the place preference boxes. Only the highest $(2.5 \mathrm{mg} / \mathrm{kg})$ dose of isradipine significantly suppressed amphetamine-induced hyperactivity in the open field. The present results suggest that isradipine interferes with amphetaminederived reinforcement at doses lower than those needed to block the acute locomotor effects of amphetamine. Given the qualitatively similar, previously reported results with verapamil, we conclude that the antireinforcing effects of the L-type calcium channel blockers cannot be exclusively explained by the suppression of psychomotor stimulation. The present results further support the notion that the L-type calcium channel blockers may be effective against stimulant addiction.[Neuropsychopharmacology 12:239-244, 1995]
KEY WORDS: Reinforcement; Place preference conditioning; Locomotor activity; Amphetamine; Isradipine; Calcium channel inhibitors; Rat

Several lines of evidence suggest that L-type calcium channel inhibitors (CCIs) may interfere with drugderived reinforcement. Calcium channel inhibitors have been demonstrated to block cocaine- and amphetamine-

From the Skipper Bowles Center for Alcohol Studies and Department of Psychiatry (OP; DHO), University of North Carolina School of Medicine, Chapel Hill, NC, and Department of Pharmacology and Physiology (AP), Institute of Psychiatry and Neurology, Warsaw, Poland.

Address correspondence to: Dr. O. Pucilowski, University of North Carolina Center for Alcohol Studies, Medical Research Bldg. A, CB\# 7175, Chapel Hill, NC 27599-7175.

Received July 28, 1994; revised October 6, 1994; accepted October 11, 1994. induced conditioned place preference in rats (Pani et al. 1991; Pucilowski et al. 1993) and to suppress intravenous cocaine self-administration in rats (Martellotta et al. 1994) and mice (Kuzmin et al. 1992). The positive reinforcing properties of psychomotor stimulants are thought to be directly correlated with their ability to induce locomotor stimulation (Wise 1990). It is hypothesized that effective pharmacological treatment for drug abuse should suppress conditioned responses, that is, reinforcing and locomotor stimulant effects, to a greater extent than the acute effects of addictive drugs. This is because potent acute antireinforcing or aversive effects of a therapeutic drug would likely compromise the necessary patient compliance with the therapy (Hursh 1993).

The ability of dihydropyridine CCIs (e.g., isradi- 
pine, nicardipine, nimodipine) to antagonize cocainederived reinforcement in the place preference conditioning and intravenous self-administration paradigms (Kuzmin et al. 1992; Martellotta et al. 1994; Pani et al. 1991) is paralleled by the potent suppression of cocaineinduced locomotor stimulation (Ansah et al. 1993; Moore et al. 1993; Pani et al. 1990) and stereotyped behavior (Ansah et al. 1993). However, amphetamineinduced locomotor stimulation and stereotypy in rats is only marginally inhibited or not affected at all by nimodipine or nicardipine (Ansah et al. 1993; MartinIverson et al. 1993; Moore et al. 1993). Interestingly enough, amphetamine-induced locomotor stimulation in mice is suppressed by high, sedative doses of some dihydropyridine CCIs (darodipine, nicardipine, nifedipine) (Grebb 1986; Renwart et al. 1986) but not the others (nimodipine, nitrendipine, nisoldipine) (Grebb 1986). In our previous study, we demonstrated that verapamil, a phenylalkylamine CCI reportedly devoid of antagonistic action against either amphetamine- (Grebb 1986; Renwart et al. 1986) or cocaine-induced locomotor stimulation (Mecke et al. 1991; Pani et al. 1990), significantly suppressed amphetamine-induced conditioned place preference (Pucilowski et al. 1993). Verapamil also failed to affect side preference on its own, indicating that it does not have aversive or rewarding properties in this paradigm. The aim of the present study was to examine the interaction of isradipine with the reinforcing effect of amphetamine using the conditioned place preference procedure. In this paradigm, repeated pairing of habit-forming drug injections (primary reward) with the distinctive environmental cues, or "place," will result in development of preference for this environment in the absence of the drug-derived reward (White et al. 1985). Conditioned place preference model offers practical advantages of technical simplicity and lack of possibly confounding operant variables (Van der Kooy 1985). The reinforcing properties of amphetamine and other stimulants have been well established using this test, and it has been suggested that they involve mesolimbic dopaminergic transmission (Spyraki et al. 1982; Van der Kooy 1985; Wise 1990).

Isradipine is a highly lipophylic dihydropyridine CCI previously demonstrated to be an efficient blocker of the reinforcing properties of cocaine (Kuzmin et al. 1992; Martellotta et al. 1994; Pani et al. 1991), morphine (Kuzmin et al. 1992), and alcohol (Fadda et al. 1992; Pucilowski et al. 1994). Isradipine, similarly to verapamil, does not appear to affect place preference conditioning on its own (Calcagnetti and Schechter 1994). Additionally, we tested the acute interaction of isradipine with the amphetamine-induced locomotor stimulation. We hypothesized that isradipine would attenuate the conditioned reinforcement but not the acute locomotor stimulatory effect of amphetamine. The results indicate that although isradipine interferes with both effects of amphetamine, it reveals its antireinforcing properties at doses lower than those required for acute suppression of locomotor stimulation.

\section{METHODS}

\section{Animals}

Male Wistar rats approximately 60 days of age and weighing a minimum of $250 \mathrm{~g}$ at the beginning of the study served as subjects. The rats used in the conditioning place preference study and for testing activity in preference boxes were purchased from Charles River (Raleigh, NC). Wistar rats used for the open field locomotor activity experiment were obtained from a licensed breeder in Warsaw, Poland. All animals were housed in groups of 2 to 3 per cage $(25 \times 45 \times 20 \mathrm{~cm})$, in a temperature-controlled room $\left(21 \pm 1^{\circ} \mathrm{C}\right)$ with free access to food and tap water.

\section{Drugs}

$( \pm)$ Isradipine (Sandoz, East Hanover, NJ) was suspended in 1\% Tween 80 (Sigma, St. Louis, MO) in saline and injected intraperitoneally (IP) in doses of 0.6 , 1.2 , and $2.5 \mathrm{mg} / \mathrm{kg}(1.6,3.2$, and $6.7 \mu \mathrm{mol} / \mathrm{kg}$, respectively). d-Amphetamine sulfate (Sigma) was dissolved in sterile saline solution and injected IP in a dose of 1 $\mathrm{mg} / \mathrm{kg}(2.7 \mu \mathrm{mol} / \mathrm{kg}$, calculated as salt $)$. Both drugs were administered in a volume of $1 \mathrm{ml} / \mathrm{kg}$.

\section{Procedures}

Place Preference Conditioning. Eight identical testing chambers, divided into two compartments equal in size $(30 \times 30 \times 30 \mathrm{~cm})$, but clearly differentiated by color (black/gray stripes vs. white), were used in the place preference conditioning experiments. The two compartments were separated by a wooden partition with a guillotine door. The positioning of a rat was detected by microswitches and the information fed directly into a custom written program for data collection running on a PC computer. This program recorded the time spent in each compartment as well as the number of crosses between the compartments over a desired time interval.

The procedure was started, beginning on day 1 , by familiarizing the rats with the apparatus. Each animal was placed in the white compartment next to the open guillotine door and allowed to explore both compartments for 30 minutes. On the next two days (day 2 and $3)$, the rats' original preference was evaluated over a 15-min period each day by recording the relative cumulative time spent on each side. The rats were then assigned to experimental groups, matched for their side bias, and the conditioning procedure was initiated.

The conditioning phase consisted of alternating 4 drug and 4 saline injection days (i.e., 8 days/pairings total). The guillotine doors were closed during this phase and each rat spent daily 30 minutes in the appropriate respective compartment. Thirty-five rats were assigned into five groups of seven rats each. Group 1 included the control rats not treated with amphetamine (i.e., saline + saline). Each in the remaining four groups received d-amphetamine injection 10 minutes prior to conditioning sessions during which rats were placed 
in the originally less preferred compartment. Forty minutes prior to amphetamine injection (and 50 minutes prior to conditioning session) each of these groups was injected with either a vehicle or one of three doses of isradipine. On alternate days every animal in each group received injections of saline paired with the originally more preferred compartment.

On the day following the last conditioning session, that is, on day 12, place preference and the number of crosses over a 15-minute period were reexamined similarly as it was done on day 2 or 3 .

Acute Effects on Locomotor Activity. Two separate experiments were performed. In the first one, the acute interaction of isradipine and amphetamine was examined in the same boxes as those used for the place preference testing. In the second, the effect of drugs on locomotor activity was evaluated in the open field. The apparatus used for that purpose (COTM, Bialystok, Poland) consisted of four identical white open-field arenas $(40 \times 40 \mathrm{~cm})$ each bound by a $30-\mathrm{cm}$ high wall made of opaque acrylic plastic. Locomotor activity was detected by 16 parallel infrared light photocell/sensors on the $X$ and 16 on the $Y$ axis, $2 \mathrm{~cm}$ above the floor level. The activity was sampled by the computer every 0.2 seconds and subsequently integrated as the total distance covered. The test was carried out in a dimly illuminated, sound insulated room between 1000 and 1200 hours under white noise conditions (provided by an electric fan).

The procedure was similar for each experiment, the only difference being the length of testing period, which was 15 minutes for activity in place preference boxes (i.e., the same as used for testing reinforcement) and 10 minutes for the open field test. On experimental day 1 the rats' baseline activity was established (Pretest). The rats were then divided into four treatment groups within each experiment and matched for their baseline activity. Two days later (day 3 ), the rats were injected with either a vehicle or isradipine. After a 30-minute break, the rats' locomotor activity was examined over a 15- or 10-minute period (Test). Immediately afterward, all rats were injected IP with amphetamine, and following, another 10-minute interval, their activity was measured again (Retest).

Twenty-four rats were used for the experiment with the place preference boxes, twenty-eight rats for the open field study. One group in each experiment was injected IP with $1 \%$ Tween $80(1 \mathrm{ml} / \mathrm{kg})$, the remaining three groups were injected with one of three doses of isradipine $(1.6,3.2$, and $6.7 \mu \mathrm{mol} / \mathrm{kg})$.

\section{Statistics}

All data are presented as means \pm SEM. The place preference data were expressed as the difference in time spent on drug-associated side from the pretest baseline. The results were analyzed with a one-way analysis of variance (ANOVA), followed by the Duncan Multiple Range test. The locomotor activity data were analyzed with the repeated measures ANOVA followed by the Scheffe's test for multiple post hoc comparisons. The $p$ value greater than .05 was considered statistically significant. Analyses were performed using the Pharm/ PCS v.4 (Tallarida and Murray 1987) and Statquick v.4 (Lundon Software, Chagrin Falls, $\mathrm{OH}$ ) statistical packages.

\section{RESULTS}

\section{Place Preference Conditioning}

There was no marked side bias among the rats used in the present experiment: the overall mean time spent in the stripped compartment was $456 \pm 51 \mathrm{~s}$, or $51 \%$ of the total test time. One-way ANOVAs revealed a significant overall treatment effect $[F(4,30)=2.91, p<$ $.05]$. Repeated amphetamine treatment has led to a significant place preference (Figure 1). Pretreatment with the lowest, $0.6-\mathrm{mg} / \mathrm{kg}$ dose of isradipine failed to modify this amphetamine-induced reinforcing effect. However, both higher doses of isradipine antagonized amphetamine-derived reinforcement in this paradigm since the mean change in time spent on drug-associated side was not different from that of the control group (i.e., the group not treated with amphetamine).

In addition, there was a significant overall treatment effect on the change in activity in the preference boxes, that is, the number of intratrial crosses $[F(4,30)-=3.02$, $p<.05]$. The baseline activity, which overall was $9 \pm$

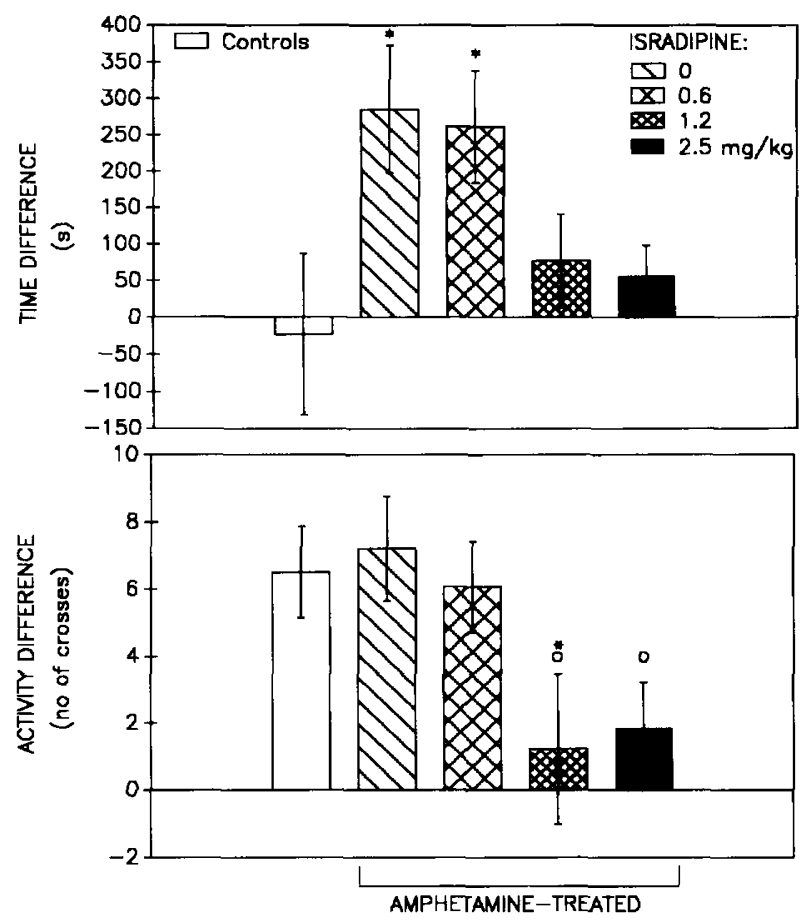

Figure 1. Effect of isradipine on amphetamine-induced place preference conditioning (upper panel) and activity (lower panel). Data expressed as means \pm SEM of seven rats per group. Time difference scores in the upper panel indicate the difference from the baseline in time spent on the drug-associated compartment. ${ }^{*} p<.05$ versus controls; ${ }^{\circ} p<.05$ versus isradipine 0 (Duncan's test). 
1 crosses per 15 minutes, increased by approximately $60 \%$ to $70 \%$ in controls as well as in amphetamineinjected groups pretreated with either the vehicle or the lowest dose of isradipine (Figure 1). Both higher doses of isradipine, which blocked the development of place preference, also significantly $(p<.05)$ suppressed that increase in the locomotor activity.

\section{Acute Effects on Locomotor Activity}

Place Preference Boxes. Repeated ANOVA measures revealed that there was no overall difference in the number of crosses between the three tests $[F(2,60)=0.37]$. Neither the treatment effect $[F(3,60)=1.22]$ nor the interaction of test $\times$ treatment effects $[F(6,60=0.24]$ were found significant. There was, however, a tendency for the two higher doses of isradipine to attenuate activity upon pairing with amphetamine (Figure 2).

Open Field. Repeated ANOVA measures revealed that there was a significant overall difference in locomotor activity scores between the three tests $[F(2,72)=17.27$, $p<.001]$. Neither the treatment effect $[F(3,72)=1.97]$ nor the interaction of test $\times$ treatment effects $[F(6,72)=$ 2] were found significant. As it is shown in Figure 3, the effect of isradipine by itself did not differ from that of the control Tween injection. Moderate increase in locomotor activity observed during the second test may be explained by the neophobic reaction to the unfamiliar open field during the pretest. There was a significant $(p<.01)$ increase in locomotor activity following amphetamine injection, as compared to the pretest values, with the exception of the group pretreated with the highest $2.5-\mathrm{mg} / \mathrm{kg}$ dose of isradipine.

\section{DISCUSSION}

The present results confirm the prediction that isradipine would suppress the rewarding effect of amphetamine in the conditioned place preference paradigm. It has been recently demonstrated by Calcagnetti and Schechter (1994) that isradipine does not produce place

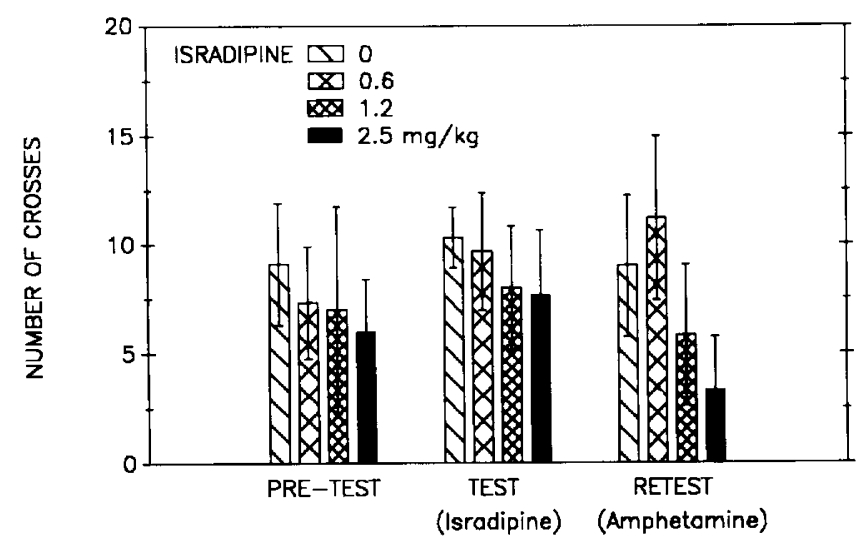

Figure 2. Acute effect of isradipine on spontaneous and amphetamine-induced locomotor activity in the place preference boxes (mean \pm SEM of six rats per group).

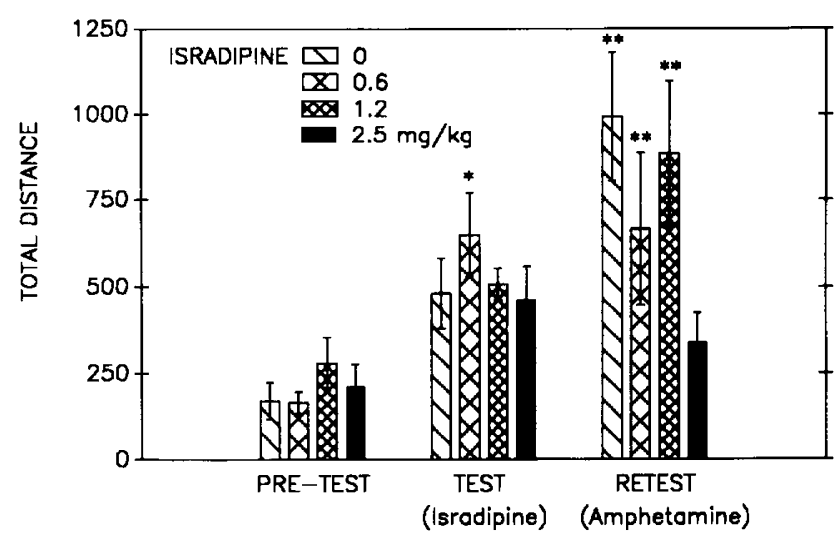

Figure 3. Acute effect of isradipine on spontaneous and amphetamine-induced locomotor activity in the open field (mean \pm SEM of seven rats per group). ${ }^{*} p<.05,{ }^{* *} p<.01$ versus pretest (baseline) values (Scheffe's test).

preference or aversion on its own. Furthermore, our present data suggest that although isradipine can attenuate amphetamine-induced locomotor activity in the open field at the highest dose used (i.e., $2.5 \mathrm{mg} / \mathrm{kg}$ ), this acute effect cannot fully account for the significant suppression of amphetamine-derived reinforcement. Isradipine injected acutely in $1.2 \mathrm{-mg} / \mathrm{kg}$ doses failed to modify amphetamine-induced locomotor stimulation in the open field, yet it caused a significant inhibition of amphetamine-induced place preference that did not differ from the effect of the highest $2.5-\mathrm{mg} / \mathrm{kg}$ dose of isradipine. Obviously, the results of the acute experiment cannot relate directly to the effects of chronic conditioning study. However, repeated pairing of an acute effect of amphetamine, such as locomotor stimulation, with a distinct set of environmental cues leads to the development of a conditioned response. Existence of this acute effect is necessary for it to be associated through the process of conditioning. It appears that 1 $\mathrm{mg} / \mathrm{kg}$ of amphetamine is a sufficient dose to produce reinforcement but not locomotor activation. It is also important to note that the number of intercompartment crosses in the place preference box does not seem to be a good index of the locomotor stimulatory effects of amphetamine. There was no clear increase in the number of crosses following injection of amphetamine in the acute experiment. In the chronic conditioning study, a similar increase in the number of crosses was observed after conditioning in control saline-treated animals as in the amphetamine-injected group. This may indicate that the increased motility (number of crosses) in the conditioning experiment is contingent on purely environmental factors and is not an effect of sensitization to amphetamine. Interestingly enough, two higher doses of isradipine $(1.2$ and $2.5 \mathrm{mg} / \mathrm{kg}$ ) caused a significant suppression of this activity increase that paralleled the inhibitory effect on amphetamine-derived reinforcement (i.e., place preference). Decreased activity in rats pretreated with two higher doses of isradipine may in fact be secondary to the suppression of amphetamine-derived reward and reflect a lack of moti- 
vation toward crossing on to amphetamine-associated territory. Taken together, these data suggest that the antireinforcing effect of isradipine may be more related to interference with the reward and less with drivelike effects of amphetamine. Similar reasoning applies to verapamil, a phenylalkylamine CCI reported to be a potent antagonist of amphetamine-induced place preference without intrinsic aversive or reinforcing properties (Pucilowski et al. 1993) and devoid of inhibitory activity against amphetamine-induced locomotor stimulation (Grebb 1986; Mecke et al. 1991; Renwart et al. 1986).

Cocaine and amphetamine are both considered to produce their stimulant and addictive effects by increasing dopaminergic transmission (Wise 1990), albeit via different mechanisms. Primary mechanism by which cocaine increases dopamine synaptic concentrations is the reuptake inhibition with additional facilitation of amine release. Amphetamine predominantly has a direct releasing action accompanied by the reuptake inhibition. If the processes affected by cocaine are both calcium-dependent, amphetamine-induced release of dopamine appears to be largely impulse- and calciumindependent (Martin-Iverson et al. 1991; McMillen 1983). Dihydropyridine, but not phenylalkylamine or benzothiazepine CCIs reportedly suppress cocaineinduced dopamine release in the nucleus accumbens (Pani et al. 1990). Thus, it has been argued that this property of CCIs may account for their ability to attenuate the drive (locomotion) and reward (place preference, self-administration) effects of cocaine. Interestingly enough, various CCIs have been generally ineffective in antagonizing amphetamine-induced dopamine release (Pani et al. 1990) or locomotor stimulation (Ansah et al. 1993; Grebb 1986; Martin-Iverson et al. 1993; Mecke et al. 1991; Moore et al. 1993; Renwart et al. 1986). It has been thus hypothesized that there is a causal relationship between the inability of CCIs to interfere with either effect of amphetamine. However, given the present results and the previous data on verapamil (Pucilowski et al. 1993), it appears that CCIs' interaction with calcium-dependent dopamine release may not be the only mechanism by which they attenuate drug-derived reward. Considerable neuroanatomical and functional evidence indicate that the $\mathrm{N}$-type calcium channels are primarily involved in presynaptic processes of neurotransmitter uptake and release, although in some cells L-type channels modulate transmitter release as well (see Porzig 1990; Sher et al. 1991, for review). On the other hand, CCI-sensitive L-type channels, owing to their postsynaptic localization (Ahlijanian et al. 1990), appear to modulate such cytosolic effects as enzyme activity regulation, channel phosphorylation, and gene expression (Ghosh 1994; Sher et al. 1991). It is possible that CCIs, in addition to modulation of amine release, interact with dopamine-initiated postsynaptic events (e.g., transmitter and hormone synthesis, impulse propagation) that are common to different drugs of abuse and that lead to an activation of cellular processes involved in drug-derived reinforcement.
We have hypothesized that CCIs may act to prevent the neuroadaptive changes brought about by various drugs interacting with the dopaminergic system activity (Pucilowski 1992). This is substantiated by the evidence that concomitant treatment with CCIs can prevent behavioral supersensitivity to dopaminergic agonists (apomorphine, quinpirole) in animals chronically administered haloperidol (Grebb et al. 1987; Pucilowski and Eichelman 1991a,b; Pucilowski and Kostowski, 1988) or alcohol (Pucilowski and Eichelman, 1991a; Pucilowski and Kostowski, 1988). Furthermore, CCIs interfere with the induction and expression of behavioral sensitization to psychomotor effects of stimulants (Karler et al. 1991) and act synergistically with neuroleptics to inhibit the unconditioned and conditioned locomotor response to amphetamine (Martin-Iverson et al. 1993). Isradipine and verapamil do not appear to be aversive in the place preference conditioning paradigm (Calcagnetti and Schechter 1994; Pucilowski et al. 1993), but direct dopaminergic antagonists do not produce place aversion either (Spyraki et al. 1982). This lack of clear aversive properties of CCIs further reinforces their potential in the treatment of drug abuse.

In conclusion, the present and previously reported data suggest that CCIs can attenuate both the psychomotor activation and the positive reinforcement elicited by amphetamine. However, suppression of amphetamine-derived reinforcement is seen at doses lower than those needed to attenuate locomotor stimulation. This suggests that the antireinforcing properties of $\mathrm{CCls}$ are not directly or exclusively related to their interference with the locomotor stimulant effect of amphetamine.

\section{ACKNOWLEDGMENTS}

The results were partially presented at the Fourth Joint Meeting of Hungarian, Italian, and Polish Pharmacological Societies, Poznan, 1994, and published in abstract form. We would like to thank Jadwiga Benko for technical assistance and Dr. David B. Weinstein and Kathleen Roskaz of Sandoz Research Institute for providing the isradipine.

\section{REFERENCES}

Ahlijanian MK, Westenbroek RE, Catterall WA (1990): Subunit structure and localization of dihydropyridinesensitive calcium channels in mammalian brain, spinal cord, and retina. Neuron 3:819-832

Ansah T-A, Wade LH, Shockley DC (1993): Effects of calcium channel entry blockers on cocaine and amphetamineinduced motor activities and toxicities. Life Sci 53:19471956

Calcagnetti DJ, Schechter MD (1994): Isradipine produces neither a conditioned place preference nor aversion. Life Sci 54:PL81-PL86

Fadda F, Garau B, Colombo G, Gessa GL (1992): Isradipine and other calcium channel antagonists attenuate ethanol consumption in ethanol-preferring rats. Alcohol Clin Exp Res 16:449-452

Ghosh A (1994): Calcium regulation of gene expression in neuronal cells. J Neurobiol 25:294-303 
Grebb JA (1986): Nifedipine and flunarizine block amphetamine-induced behavioral stimulation in mice. Life Sci 38:2375-2381

Grebb JA, Shelton RC, Freed WJ (1987): Diltiazem and verapamil prevent haloperidol-induced apomorphine supersensitivity in mice. J Neural Transm 68:241-255

Hursch SR (1993): Behavioral economics of drug selfadministration: An introduction. Drug Alcohol Depend 33:165-172

Karler R, Turkanis SA, Partlow LM, Calder LD (1991): Calcium channel blockade and behavioral sensitization. Life Sci 49:165-170

Kuzmin A, Zvartau E, Gessa GL, Martellotta MC, Fratta W (1992): Calcium antagonists isradipine and nimodipine suppress cocaine and morphine intravenous self-administration in drug-naive mice. Pharmacol Biochem Behav 41:497-500

Martellotta MC, Kuzmin A, Muglia P, Gessa GL, Fratta W (1994): Effects of the calcium antagonist isradipine on cocaine intravenous self-administration in rats. Psychopharmacology 113:378-380

Martin-Iverson MT, DiLullo SL, Reimer AL (1993): Nimodipine and haloperidol interactions in amphetamine- and cocaine-conditioned behaviors. Drugs Develop 2:417-433

Martin-Iverson MT, Yamada N, By AW, Lodge B (1991): "Designer" amphetamines: Effects on behavior and monoamines with or without reserpine and/or $\alpha$-methylp-tyrosine pretreatment. J Psychiatr Neurosci 16:253-261

McMillen BA (1983): CNS stimulants: Two distinct mechanisms of action for amphetamine-like drugs. Trends Pharmacol Sci 3:429-432

Mecke E, Kauppila T, Carlson S, Pertovaara A (1991): Differential effects of verapamil, a calcium channel antagonist, on morphine and cocaine-induced analgesia and locomotor behavior in rats. Neurosci Res Commun 9:137-141

Moore NA, Rees G, Sanger G, Awere S (1993): Effect of L-type calcium channel modulators on stimulant-induced hyperactivity. Neuropharmacology 32:719-720

Pani L, Kuzmin A, Martellotta MC, Gessa GL, Fratta W (1991): The calcium antagonist PN 200-110 inhibits the reinforcing properties of cocaine. Brain Res Bull 26:445-447

Pani L, Kuzmin A, Diana M, De Montis G, Gessa GL, Rossetti ZL (1990): Calcium receptor antagonists modify cocaine effects in the central nervous system differently. Eur J Pharmacol 190:217-221

Porzig H (1990): Pharmacological modulation of voltagedependent calcium channels in intact cells. Rev Physiol Biochem Pharmacol 114:200-262
Pucilowski O (1992): Psychopharmacological properties of calcium channel inhibitors. Psychopharmacology 109:12-29

Pucilowski O, Eichelman B (1991a): Nicardipine protects against chronic ethanol- or haloperidol-induced supersensitivity to apomorphine-induced aggression. Neuropsychopharmacology 5:55-60

Pucilowski O, Eichelman B (1991b): Diltiazem suppresses quinpirole-induced oral stereotypies in haloperidol withdrawn rats. Prog Neuropsychopharmacol Biol Psychiatry 15:717--722

Pucilowski O, Kostowski W (1988): Diltiazem suppresses apomorphine-induced fighting and pro-aggressive effect of withdrawal from chronic ethanol or haloperidol in rats. Neurosci Lett 93:96-100

Pucilowski O, Rezvani AH, Overstreet DH, Janowsky DS (1994): Calcium channel inhibitors attenuate consumption of ethanol, sucrose and saccharin solutions in rats. Behav Pharmacol 5:494-501

Pucilowski O, Garges PL, Rezvani AH, Hutcheson S, Janowsky DS (1993): Verapamil suppresses d-amphetamine-induced place preference conditioning. Eur J Pharmacol 240:89-92

Renwart N, Frances H, Simon P (1986): The calcium entry blockers: Anti-manic drugs? Prog Neuropsychopharmacol Biol Psychiatry 10:717-722

Sher E, Biancardi E, Passafaro M, Clementi F (1991): Physiopathology of neuronal voltage-operated calcium channels. FASEB J 5:2677-2683

Spyraki C, Fibiger HC, Phillips AG (1982): Dopaminergic substrates of amphetamine-induced place preference conditioning. Brain Res 253:185-193

Tallarida RJ, Murray RB (1987): Manual of Pharmacologic Calculations with Computer Programs, New York: Springer

Van der Kooy D (1985): Place conditioning: A simple and effective method for assessing the motivational properties of drugs. In Bozarth MA (ed), Methods of Assessing the Reinforcing Properties of Abused Drugs, New York: Springer, pp 229-240

White NM, Messier C, Carr GD (1985): Operationalizing and measuring the organising influence of drugs on behavior. In Bozarth MA (ed), Methods of Assessing the Reinforcing Properties of Abused Drugs, New York: Springer, pp 591-618

Wise RA (1990): The role of reward pathways in the development of drug dependence. In Balfour DJK (ed), International Encyclopedia of Pharmacology and Therapeutics, sect. 130. Psychotropic Drugs of Abuse, Elmsford, NY: Pergamon, pp 23-58 